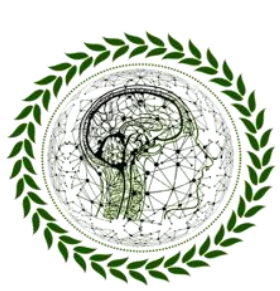

PhI Scientific Review

ISSN 2676 - 0444

Submetido em: 15/01/2022 | Aceito em: 25/01/2022 | Publicado em: 25/01/2022 | Artigo

\title{
A GESTÃo PÚBLICA E A INFLUÊNCIA NA CRIMINOLOGIA CRÍTICA E DOS DIREITOS HUMANOS
}

Fernando Lannes Villela ${ }^{1}$

Resumo: $\mathrm{O}$ trabalho apresenta uma breve reflexão acerca da gestão pública nacional e a influência no racismo institucional no sistema de repressão criminal brasileiro e o consequente superencarceramento de pessoas negras a partir de elementos da criminologia crítica, confirmados pelos dados estatísticos que evidenciam o permanente estado de violação dos direitos humanos desse grupo racial, manifestadamente vítima de um Direito Penal seletivo.

Palavras - chave: Superencarceramento, Racismo, Direitos Humanos, Criminologia Crítica.

\begin{abstract}
The work presents a brief reflection on national public management and the influence on institutional racism in the Brazilian criminal repression system and the consequent over-incarceration of black people based on elements of critical criminology, confirmed by statistical data that show the permanent state of violation of the human rights of this racial group, manifestly victim of selective criminal law.
\end{abstract}

Keywords: Over-incarceration, Racism, Human Rights, Critical Criminology.

${ }^{1}$ Bacharel em Direito pela Universidade Estácio de Sá - UniEstácio.

http://www.revistaphd.periodikos.com.br

DOI: http://doi.org/10.53497/phdsr2n1-003

V. 02, No 01, janeiro de 2022

Todos os direitos reservados $($ ) 


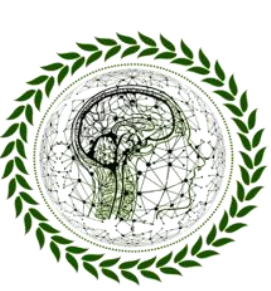

PhD Seientific Review

ISSN 2676 - 0444

\section{INTRODUÇÃO}

A lei abstrata preconiza um direito penal igualitário e imparcial, entretanto, sua aplicação demonstra-se bastante seletiva e encontra predominantemente nos grupos menos favorecidos da população seus destinatários, em especial os negros.

A referida seletividade de caráter racial confirma-se nas estatísticas, haja vista que de acordo com o informativo do Infopen (Levantamento Nacional de Informações Penitenciárias), publicado em dezembro de 2017, 64\% dos presos no Brasil são negros.

A criminologia crítica aborda essa realidade seletiva do sistema penal e a contrapõe com a dogmática penal e seu pretenso discurso igualitário, deveras formal e dissociado da atual realidade do sistema de justiça criminal e da sociedade brasileira.

Destarte, escondida sob o discurso de um direito penal igual para todos, foi construída uma política criminal seletiva, baseada no racismo, na criminalização da pobreza e responsável pelo superencarceramento e permanente estado de violação dos direitos humanos dos negros no Brasil.

Para tratar do tema, far-se-á um breve histórico das escolas criminológicas, culminando com a tendência mais contemporânea, a Escola Criminológica Critica, trazendo seus apontamentos sobre a seletividade e racismo nos órgãos responsáveis pela repressão penal no Brasil e o consequente superencarceramento dos negros, que 


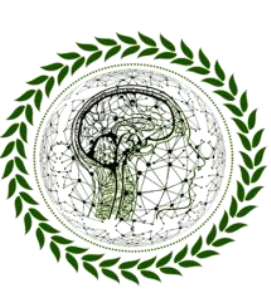

PhD Seientific Review

ISSN 2676 - 0444

em decorrência dessa prática institucional têm seus direitos humanos constantemente violados.

\section{DESENVOLVIMENTO}

Para compreender o racismo institucional no sistema de justiça criminal e o consequente superencarceramento de indivíduos negros no Brasil é indispensável traçar uma breve evolução sobre as escolas que se dedicaram ao estudo do crime e do comportamento criminoso.

É sabido que os regimes absolutistas na Idade Média utilizavam penas cruéis e desproporcionais contra seus acusados. Esse comportamento serviu de premissa para o surgimento da Escola Criminológica Clássica, que propôs a partir do pensamento Iluminista, centrado na razão, a ideia de punição na estrita medida, ou seja, o doseamento racional da pena.

Foucault (2008) na obra clássica “Vigiar e Punir”, publicada em 1975, pontua que a pena de prisão surgiu como uma sofisticação do modelo estatal para exercício da disciplina e do poder, em substituição, por exemplo, as cerimônias públicas de execução.

É recorrente na obra de diversos autores que o marco inicial da Escola Clássica foi a notável obra "Dos Delitos e das Penas" de Cesare Beccaria (2006), originalmente publicada em 1764, onde primeiramente foi abordada a questão da necessidade de utilização de critérios de proporcionalidade no dosimetria das penas.

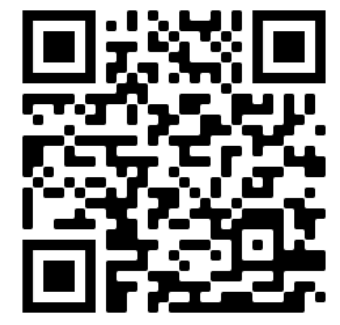

http://www.revistaphd.periodikos.com.br DOI: http://doi.org/10.53497/phdsr2n1-003

V. 02, No 01, janeiro de 2022 Todos os direitos reservados $($ ) 


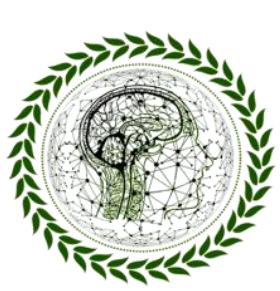

PhD Seientific Review

ISSN 2676 - 1444

Em contraposição aos espetáculos de barbárie que marcaram os antigos regimes, surgiu a ideia da pena como a medida racional retributiva à conduta criminosa e não como um recurso utilizado para imposição de castigos corporais no acusado através de espetáculos de sofrimento e aflição.

Nesse contexto surge a ideia de "Direito Penal do Fato", baseada na valoração da conduta delituosa em detrimento da autoria do delito, na medida em que o criminoso deve deixar de ser considerado um anormal, degenerado, para que a pena retribua com exatidão e racionalidade o desvio cometido.

Outra perspectiva surge com a Escola Positivista, uma vez que esta se contrapõe à Escola Clássica ao transferir para o criminoso o enfoque criminológico, em uma espécie de "Direito Penal do Autor".

Em 1876, foi publicada a obra considerada o marco inicial da Escola Positivista ou Italiana, "O Homem Delinquente", de autoria do médico italiano Cesare Lombroso, que junto aos compatriotas, Enrico Ferri e Rafael Garófalo são considerados os principais expoentes da referida escola doutrinária, ainda que tenham apresentado suas contribuições com enfoques diversos.

O crime, sob a ótica da Escola Positivista, é considerado o produto da perversão do criminoso, perversão esta que estaria predeterminada por fatores de natureza biológica do indivíduo.

Assim, o Direito Penal se reservaria apenas ao controle dos impulsos criminosos próprios dos sujeitos que teriam uma tendência natural para o crime, em oposição à tese da Escola Clássica da responsabilidade penal embasada no livre-

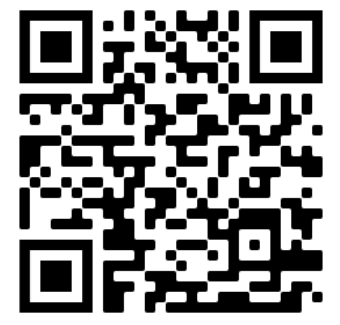

http://www.revistaphd.periodikos.com.br DOI: http://doi.org/10.53497/phdsr2n1-003

V. 02, No 01, janeiro de 2022 Todos os direitos reservados (C) 


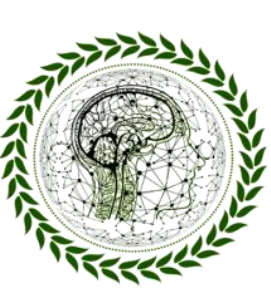

PhD Seientific Review

ISSN 2676 - 0444

arbítrio.

A respeito da Escola Positivista, Batista, preceitua:

\begin{abstract}
“Na criminologia, o positivismo transfere o objeto do delito demarcado juridicamente para a pessoa do delinquente. Contra os perigos revolucionários da ideia de igualdade, nada melhor do que uma legitimação científica da desigualdade.O criminoso biologicamente ontológico, vai demandar mais pena, mais poder punitivo indeterminado: corrigir a natureza demanda tempo" (2012, p. 45).
\end{abstract}

Nesse diapasão Ferri afirma que a defesa social contra a criminalidade é a função suprema e imanente do Estado e a razão da justiça penal (1998, p. 70).

A defesa social, na concepção da escola positiva, deve ser compreendida como a salvaguarda da sociedade contra os criminosos através da forte repressão aos indivíduos considerados perigosos.

De acordo com Baratta, a chamada Ideologia da Defesa Social já tinha lugar durante a revolução burguesa e constitui um legado da Escola Clássica para a Escola Positivista (2002, p. 70).

Apesar das diferentes concepções que cada Escola possuía e da defesa da Escola Clássica acerca da necessidade limitações ao poder de punir, no que concerne ao banimento das penas cruéis, em ambas, observou-se a existência de uma ideologia de defesa social, na medida em que a Escola Clássica sofreu apenas algumas adaptações, da Escola Positiva.

Conforme exposto, a Escola Clássica compreendia a pena como um instrumento de proteção social que deveria ser aplicada proporcionalmente ao injusto cometido para ser capaz de eliminar o perigo da impunidade e 


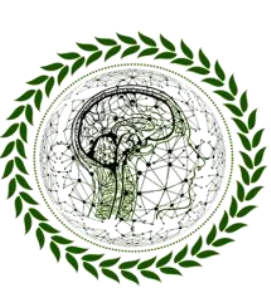

PhD Seientific Review

ISSN 2676 - (1444

consequentemente obstar a reincidência e o cometimento de outros crimes por outros indivíduos. A Escola Positivista, por sua vez, concebia a pena como meio de proteger a sociedade do criminoso.

Isto posto, verifica-se que em ambas as escolas existe a preocupação com a defesa da sociedade diante da conduta criminosa ou em outras palavras, a proteção da ordem social por meio da eliminação da malignidade que a transgressão representa.

Dessa forma, os pressupostos da Ideologia da Defesa Social, concebidos com base nas contribuições dos pensadores das Escolas Clássica e Positiva, são utilizados como justificativa para que o Direito Penal seja o instrumento de aplicação de punições aos chamados delinquentes. Desconsidera-se, deste modo, que a gênese do Direito Penal aponta sua natureza de conjunto de garantias do indivíduo frente ao direito de punir do Estado.

Já no século XX, quando surgem as Teorias Sociológicas Americanas, o modelo da defesa social, defendido pelas duas as escolas até aqui mencionadas é confrontado pelo paradigma da reação social.

Com a chegada do paradigma da reação social, ocorre um deslocamento no critério de estudo da criminalidade, tradicionalmente abordados mediante análise das causas ou das origens do crime, para percebê-la como um fenômeno social derivado do processo de interação.

Sob esta ótica, a sociologia norte-americana se amplifica a partir de um movimento intelectual conhecido como Escola de Chicago, responsável por realizar

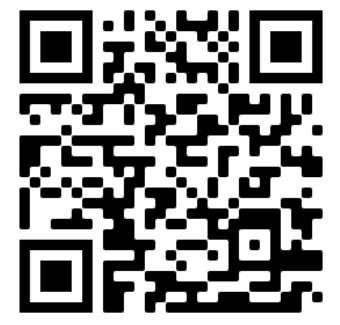




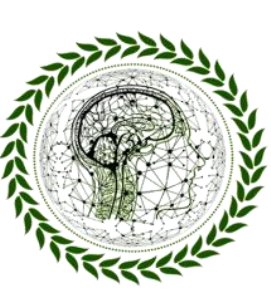

PhD Seientific Review

ISSN 2676 - 1444

pesquisas relativas à criminalidade urbana, a qual sob esse viés teórico era entendida como consequência da desorganização e desigualdade social dos grandes centros urbanos. As contribuições da Escola de Chicago são consideradas a origem de modernas teorias criminológicas, como a escola do labelling approach e a criminologia crítica.

A Labeling Approach Theory, ou Teoria do Etiquetamento Social, baseia-se na ideia de que os conceitos de crime e criminoso são construídos socialmente através de previsões legais e atos de órgãos de controle social sobre o comportamento de determinados indivíduos, em outras palavras, o labelling approach traz pela primeira vez o entendimento de que o delito não seria uma conduta criminosa em si, mas produto de uma definição feita pelos órgãos estatais responsáveis pela repressão penal. Somente após ser definida, a conduta delituosa seria considerada como tal. Sem a definição, porém, a conduta seria considerada normal e aceita.

A partir da teoria do labelling approach, o crime começa a ser entendido não como algo intrínseco e determinado, e sim como um corolário de critérios seletivos e discriminatórios que o classificam como tal, Assim, há um deslocamento do enfoque, do desvio, ou do desviante, para os processos de criminalização, de modo a confrontar, nas palavras de Vera Malaguti Batista, a ficção do "delito natural" que antes acompanhava a criminologia (2012, p.75).

Sucintamente, Conde e Hassemer explicam que a teoria do etiquetamento defende que a criminalidade não é um atributo de determinada conduta, e sim a repercussão de um processo de estigmatização da conduta e daquele que a cometeu

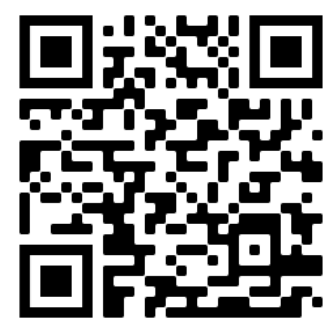

http://www.revistaphd.periodikos.com.br DOI: http://doi.org/10.53497/phdsr2n1-003

V. 02, No 01, janeiro de 2022 Todos os direitos reservados ( 


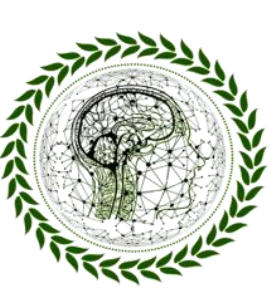

PhD Seientific Review

ISSN 2676 - (144

(2008, p.110-111).

Outra contribuição do labelling approach, é apresentada por Alessandro Baratta ao afirmar que a teoria "lançou luz sobre o fato de que o poder de criminalização, e o exercício deste poder, estão estreitamente ligados à estratificação e à estrutura antagônica da sociedade" (1997, p. 113).

Assim, a teoria ao ressaltar forma nociva como os órgãos que exercem controle social distribuem rótulos e etiquetam negativamente os indivíduos, deslegitima o princípio da igualdade no Direito Penal.

Sendo assim, na medida em que a tese suscitada pelo labelling approach desviou o enfoque do Direito Penal do crime para os processos de criminalização, podemos afirmar que a criminalização incide diferentemente sob cada um das camadas sociais e pende aplicar-se de forma majoritária a população historicamente desfavorecida, dentre os quais estão incluídos os negros.

Amparada nesse entendimento surge a Escola Criminológica Crítica, que a partir de teorias políticas e econômicas do crime, passou a analisar as causas sociais e institucionais do delito, além de propor uma reflexão sobre a seletividade do sistema penal brasileiro, a ideologia dominante entre os atores deste sistema e a desproporcionalidade na distribuição da Justiça penal, uma vez que esta se destina prioritária e quase exclusivamente na persecução dos indivíduos pobres, marginalizados e estigmatizados, em sua maioria negros.

Nesse sentido, Zaffaroni ressalta que o Direito Penal é direcionado para selecionar os crimes cometidos pelos setores mais vulneráveis da sociedade ao

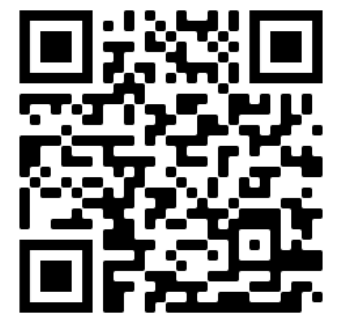

http://www.revistaphd.periodikos.com.br DOI: http://doi.org/10.53497/phdsr2n1-003

V. 02, No 01, janeiro de 2022 Todos os direitos reservados $($ ) 


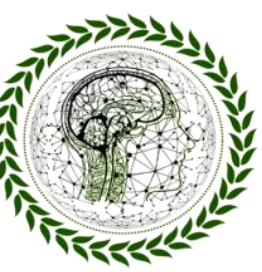

PhD Scientific Review

ISSN 2676 - 0444

afirmar que "se todos os furtos, adultérios, abortos, defraudações, falsidades, subornos, lesões e ameaças fossem concretamente criminalizados, praticamente não haveria habitante que não fosse, por diversas vezes, criminalizados" (2001, p. 26).

Sendo assim, como é impossível que sistema penal puna todas as condutas delituosas é necessário que ocorra uma seleção, e neste tocante citamos o aspecto político que Foucault (2008) nomeou de "gestão diferencial dos ilegalismos".

Diante da impossibilidade de atingir a todos os indivíduos igualitariamente, a via utilizada pelos órgãos de repressão penal é a seletividade, observa Zaffaroni e Pierangeli que o sistema de repressão penal seleciona indivíduos ou condutas e os criminaliza de acordo com classe e posição social, em uma inequívoca manifestação de que não somos todos igualmente submetidos ao sistema penal, o qual se baseia em 'estereótipos' que detêm características das camadas sociais marginalizadas e humilde (2011, p. 73).

A criminologia brasileira aponta para a seletividade do sistema penal como uma forma característica de violência e criminalização perpetradas em face de cidadãos das classes menos abastadas, em especial os jovens negros.

Nesse sentido, preleciona Carvalho que :

[...] a seletividade racial é uma constante na historiografia dos sistemas punitivos, podendo ser ocultada pela incidência de algumas variáveis autônomas. Porém no Brasil, a população jovem negra, especificamente aquela oriunda das periferias das grandes cidades, são as vítimas preferenciais das execuções encobertas pelos famigerados "autos de resistência" e do superencarceramento, o que aponta que o racismo se aplica como uma espécie de "metarregra interpretativa da seletividade", indicando a existência de um racismo estrutural e, não tão somente, conjuntural do sistema de repressão penal (2014, p. 649).

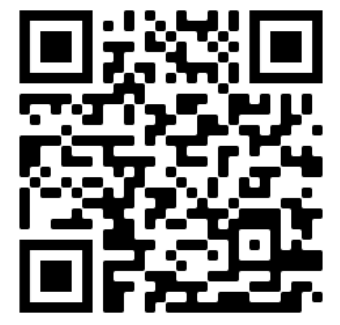

http://www.revistaphd.periodikos.com.br DOI: http://doi.org/10.53497/phdsr2n1-003

V. 02, No 01, janeiro de 2022 Todos os direitos reservados (C) 


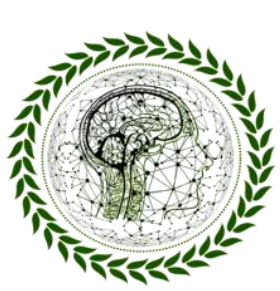

PhD Seientific Review

ISSN 2676 - 1444

A mencionada seletividade racial confirma-se no último relatório do Infopen (Levantamento Nacional de Informações Penitenciárias), divulgado em dezembro de 2017, o qual aponta que 64\% dos presos no Brasil são negros.

Sendo assim, estatisticamente, a probabilidade de criminalização de uma conduta perpetrada por um individuo branco é inferior a probabilidade de que a mesma conduta, dessa vez perpetrada por um individuo seja criminalizado.

Para tanto, Zaffaroni ressalta para eleger e criminalizar um indivíduo é necessário que o mesmo tenha praticado uma ação. Assim os órgãos primários do Sistema Penal, notadamente polícia, selecionam seus candidatos à criminalização e os apresentam ao poder judiciário, que por sua vez, não é capaz de eliminar a seletividade, apenas operando uma tímida redução (2001, p. 245-246).

Tal prática ocasionou ao longo dos anos o superencarceramento no sistema prisional brasileiro de indivíduos negros, contrariando o mito da democracia racial, o qual preceitua que no Brasil e em outros países da América Latina não ocorreu a discriminação racial, como em outros países com histórico escravocrata, especificamente os Estados Unidos.

Sobre o tema, Lília Schwarcz, apropriando-se das palavras de Lévi-Strauss, quando afirmou que o mito se 'extenua sem por isso desaparecer', pontua que a oportunidade do mito permanece para além de sua desconstrução racional, o que faz com que, ainda que se admita a existência do preconceito, no Brasil, a ideia de harmonia racial se impõe às evidencias e à própria consciência da discriminação

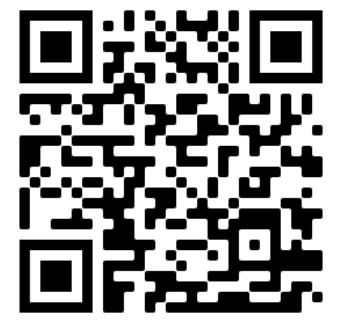

http://www.revistaphd.periodikos.com.br DOI: http://doi.org/10.53497/phdsr2n1-003

V. 02, No 01, janeiro de 2022 Todos os direitos reservados $($ ) 


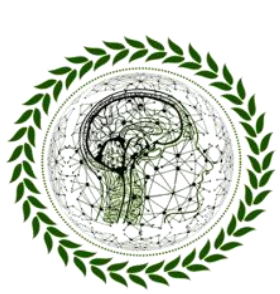

PhI Scientific Review

ISSN 2676 - 0444

(1999, p. 309).

O mencionado superencarceramento de indivíduos negra, contribuiu de sobremaneira para a falência do sistema prisional brasileiro, que na está apto a acomodar tantos indivíduos e enfrenta a superlotação, uso de drogas, falta de pessoal, epidemias, motins e rebeliões, facções criminosas estabelecidas dentro das unidades eu uma série de outras situações que tornam a vida nos cárceres degradante e desumana.

Diante da inércia dos poderes públicos em transformar essa realidade, essa população, conforme dito, em sua maioria negra, está sujeita a crueldade do sistema e privada de seus direitos humanos mais básicos enquanto cumprem penas privativas de liberdade.

É sabido que o direito positivo brasileiro e as normas internacionais na qual é signatário protegem os direitos e as garantias dos indivíduos privados de liberdade de modo a resguardar sua dignidade, entretanto também é de conhecimento público a falência do sistema prisional brasileiro, no que se refere ao tratamento ofertado aos seus detentos.

\section{RESULTADOS}

Ao longo deste trabalho buscou-se através de uma breve exposição sobre as escolas penais e a evolução do pensamento criminológico, a reflexão sobre a realidade do sistema repressivo penal brasileiro e suas práticas seletivas, ao eleger

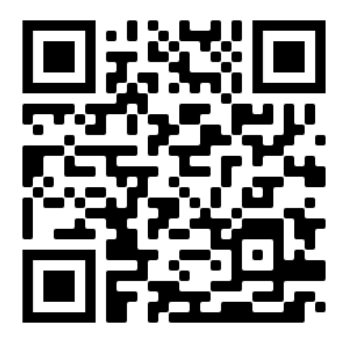

http://www.revistaphd.periodikos.com.br DOI: http://doi.org/10.53497/phdsr2n1-003

V. 02, No 01, janeiro de 2022 Todos os direitos reservados ( 


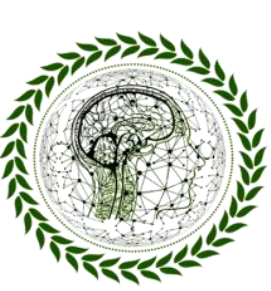

PhD Seientific Review

ISSN 2676 - 0444

seus indivíduos, em sua maioria negros e pobres, ocasionando a superlotação de cárceres de cidadãos com um perfil predeterminado.

O debate proposto pelas escolas criminológicas contemporâneas, em a crítica, revelou que existe uma orientação velada de classe e de raça que orienta a atuação dos órgãos de repressão penal, em especial a polícia.

A constatação desse cenário ocorre não só pela contribuição de teóricos, como também em forma de estatística, haja vista que conforme divulgada pelo Infopen (Levantamento Nacional de Informações Penitenciárias), em seu último relatório do divulgado em dezembro de 2017, o Brasil possui a terceira maior população carcerária do mundo e a que apresenta o maior crescimento, atingindo o numero de 726.712 pessoas privadas de liberdade, das quais $64 \%$ são negras e de baixa escolaridade, uma vez que $80 \%$ não concluiu o Ensino Médio e $0 \%$ possui Ensino Superior Completo.

Como se não bastasse, dentro do sistema prisional essas pessoas privadas de liberdade sofrem inúmeras violações aos seus direitos humanos, um vez que o sistema carcerário brasileiro não está apto acolher o elevado número de detentos neles recolhidos.

O presente trabalho, não esgotou a discussão proposta, uma vez que a sumariedade do trabalho não permitiria, entretanto é possível afirmar que não é por acaso que a maioria da população carcerária brasileira seja composta por indivíduos negros, e não é por acaso que a sanção penal atinja prioritariamente a população negra.

http://www.revistaphd.periodikos.com.br DOI: http://doi.org/10.53497/phdsr2n1-003

V. 02, No 01, janeiro de 2022 Todos os direitos reservados ( 


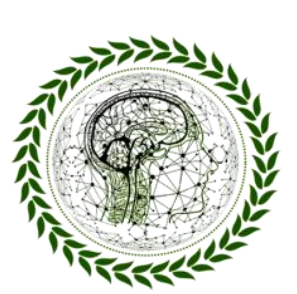

PhD Seientific Review

ISSN 2676 - 0444

\section{REFERÊNCIAS}

BATISTA, Vera Malaguti. Introdução crítica a criminologia brasileira. 2. ed. Rio de Janeiro: Revan, 2012.

BARATTA, Alessandro. Criminologia crítica e crítica do direito penal: introdução à sociologia do direito penal. Tradução de: Juarez Cirino dos Santos. 3. ed. Rio de Janeiro: Revan, 2002. p. 41.

BRASIL. Departamento Penitenciário Nacional. Ministério da Justiça. Levantamento Nacional de Informações Penitenciárias - INFOPEN - Junho de 2016 [online]. Disponível em: $\quad$ http://www.justica.gov.br/news/ha-726-712-pessoas-presas-nobrasil/relatorio 2016 junho.pdf. Acesso em: 27 mar. 2017

BECCARIA, Cesare. Dos delitos e das penas. 3.ed. rev. Trad. de J. Cretella Jr. e Agnes Cretella. São Paulo: Revista dos Tribunais, 2006.

- Foucault, Michel. Vigiar e punir: nascimento da prisão. 36.ed. Petrópolis: Vozes, 2009.

CARVALHO, Salo de. O encarceramento seletivo da juventude negra brasileira: a decisiva contribuição do Poder Judiciário.Rev. Fac. Direito UFMG, Belo Horizonte, n. 67, pp. 623 - 652, jul./dez. 2015.

CONDE, Francisco Muñoz, HASSEMER, Winfried. Introdução à Criminologia. Rio de Janeiro: Lumen Juris, 2008.

FERRI, Enrico. Princípios do Direito Criminal: o criminoso e o crime.Tradução de Paolo Capitanio. 2ª ed. Campinas: Bookseller,1998.

FOUCAULT, Michel. Vigiar e punir: nascimento da prisão. 35.ed. Petrópolis, RJ: Vozes,

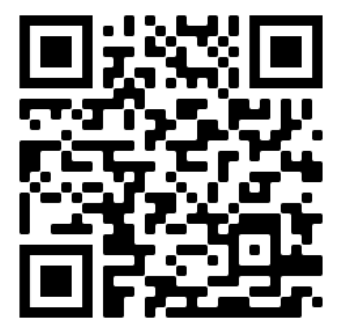


2008.

LYRA, Roberto. Novas escolas penais. Rio de Janeiro: Canton e Reide, 1936, p. 40.

SCHWARCZ, Lilia. 1999. "Questão Racial e Etnicidade". In MICELI, Sérgio org. O que ler na Ciência Social Brasileira (1970 - 1995). Antropologia Vol. II, Sumaré e ANPOCS, São Paulo, pp. 267-326.

ZAFFARONI, Eugenio Raul; PIERANGELI, José Henrique. Manual de Direito Penal Brasileiro, volume 1: Parte Geral. 9. ed. São Paulo: Editora Revista dos Tribunais, 2011. 